\title{
Myxoedema presenting with severe laryngeal obstruction
}

\author{
L. ERWIN \\ M.B., Ch.B., M.R.C.P. (UK) \\ University Department of Medicine, Royal Infirmary, Glasgow G4 OSF
}

\begin{abstract}
Summary
A patient with myxoedema developed severe laryngeal obstruction following an upper respiratory tract infection. Attention is drawn to this unusual but potentially fatal complication of myxoedema.

\section{Introduction}

Thickening or oedema of the vocal cords and myxoedematous infiltration of the laryngeal submucosa may be responsible for the laryngeal symptoms of myxoedema in some patients, but respiratory difficulty due to laryngeal obstruction is extremely rare as a complication of myxoedema. If, however, upper respiratory tract infection is superimposed on a myxoedematous larynx an acute emergency may be precipitated, as in this patient.
\end{abstract}

\section{Case report}

A 48-year-old man with a 15-year history of chronic bronchitis and chronic alcoholism was discovered to be hypothyroid in 1975 . Thyroxine $0.15 \mathrm{mg} /$ day was commenced, but he defaulted from follow-up. During several admissions for detoxification, thyroid function tests suggested that he had stopped taking his thyroxine.

Several months before his latest admission he noticed cold intolerance, poor appetite, poor concentration, weight-gain, and increasing huskiness of his voice. For 2 weeks before admission he had a 'flu-like illness with a wheeze and dry cough. Salbutamol inhaler and antibiotics were prescribed without benefit. Rapidly progressive respiratory difficulty ensued, requiring urgent admission and endotracheal intubation.

On examination he was obese, pale, grossly myxoedematous and in severe respiratory distress with loud stridor, cyanosis, and hypoxic seizures. Pulse rate was $100 / \mathrm{min}$ and blood pressure $100 / 60$ $\mathrm{mmHg}$. A small, smooth goitre was palpable. There was ascites but no hepatomegaly or splenomegaly. Within $5 \mathrm{~min}$ of endotracheal intubation he was fully conscious and had removed the endotracheal tube. His respiratory difficulty and stridor persisted, however, with obviously increasing distress. Tracheo- stomy was performed with complete relief of symptoms. Direct laryngoscopy revealed gross oedema of the ventricular folds, presumed due to upper respiratory tract infection of a myxoedematous larynx.

Arterial blood gases on admission showed profound hypoxia with a $P_{2}$ of $38 \mathrm{mmHg}, P_{\mathrm{CO}_{2}}$ of $88 \mathrm{mmHg}, \mathrm{pH}$ of $7 \cdot 1$ and base excess of $-2 \mathrm{mmol} / \mathrm{l}$. Repeat analysis after tracheostomy showed normal results with a $\mathrm{PO}_{2}$ of $98 \mathrm{mmHg}$. $\mathrm{PCO}_{2}$ of $38 \mathrm{mmHg}$, $\mathrm{pH}$ of 7.37 and base excess of $+1 \mathrm{mmol} / \mathrm{l}$. Other investigations revealed $T_{4}$ of $20 \mathrm{mmol} / \mathrm{l}$ (normal, $55-144$ ), $T_{3} 0 \cdot 7 \mathrm{nmol} / 1$ (normal, $0 \cdot 9-2 \cdot 8$ ), TSH $42 \cdot 4$ mu./1 (normal, 0-8.0). Haemoglobin was $10 \cdot 6 \mathrm{~g} / \mathrm{dl}$. Electrocardiogram showed low voltage complexes. Chest X-ray showed changes consistent with chronic obstructive airways disease. A lateral soft tissue Xray of neck showed laryngeal soft tissue thickening.

Replacement thyroxine $(0.3 \mathrm{mg} /$ day $)$ was given with a gradual clinical improvement in his myxoedema and serial thyroid function tests returned to normal after 3 weeks. Direct laryngoscopy was repeated at 2 weeks, marked oedema of the supraglottis and vocal cords being noted. The tracheostomy was closed uneventfully one week later at which point the patient's respiratory status was clinically normal.

\section{Discussion}

Tracheal compression by various thyroid pathologies is a well recognized cause of respiratory embarrassment but it is very uncommon for myxoedema to predispose to laryngeal obstruction. Thickening and oedema of the vocal cords becomes increasingly common as the degree of myxoedema worsens (Gupta et al., 1977). This is probably owing to the presence of mucin in the sub-epithelial space as indicated by Alcian Blue staining of myxoedematous vocal cords (Bicknell, 1973). Severe myxoedema alone probably will not lead to laryngeal obstruction, as other manifestations of the disease will bring the patient to medical attention. In this case, an upper respiratory tract infection led 
to further inflammatory oedema of an already swollen laryngeal mucosa. The infecting agent was probably Chlamydia B (serological titre $1: 128$ ) although the patient did not recollect exposure to birds of any species. Unfortunately, convalescent serum was not available for further viral studies.

While it is recognized that the patient's extreme reluctance to seek or follow medical advice was probably responsible for his presentation, the case illustrates another potentially fatal complication of myxoedema.
Acknowledgments

I thank Mr G. G. Browning, Senior Lecturer in Otolaryngology, for permission to report this case.

\section{References}

BICKNELL, P.G. (1973) Mild hypothyroidism and its effects on the larynx. Journal of Laryngology and Otology, 87, 123.

Gupta, O.P., Bhatia, P.L., Agarwal, M.K., Mehrotra, M.L. \& Mishr, S.K. (1977) Nasal, pharyngeal and laryngeal manifestations of hypothyroidism. Ear, Nose and Throat Journal, 56, 349. 